\title{
ARIMA Model for Forecasting COVID-19 in East Java
}

\author{
E S Nugraha* A H Ulya
}

\author{
School of Business, Study Program of Actuarial Science, President University, Cikarang, Bekasi 17550, Indonesia \\ *E S Nugraha. Email: edwin.nugraha@president.ac.id
}

\begin{abstract}
Coronavirus is a group of viruses that can cause disease in both humans and animals. The newly discovered coronavirus triggers COVID-19 disease. COVID-19 is now a pandemic that is emerging in many countries around the world, including Indonesia. Several sectors have been affected as a result of this pandemic, such as medical, economics, government, industry, etc. By using ARIMA model, we try to predict the daily cases of COVID-19 that occur in East Java. We obtained this model with the help of R software. The best model we obtained was the ARIMA model $(7,1,7)$, which we used to predict the next 14 days from November 1, 2020, to November 14, 2020. The results of forecasting obtained by comparing real data with a $99 \%$ confidence interval, we obtained that the forecasting results are close to the real data that has occurred until November 14, 2020. This prediction is expected to help various sectors affected by this pandemic, such as government, economy, health especially in East Java.
\end{abstract}

Keywords: COVID-19, Statistical Modelling, Time Series Analysis, ARIMA.

\section{INTRODUCTION}

Based on government data seen by the South China Morning Post (SCMP), the first case of Coronavirus Disease occurred on November 17, 2019, which infected a 55-year-old person from Hubei province [1]. Furthermore, this disease is known as COVID-19 which stands for Coronavirus Disease 2019. Until now, almost every country in the world still fight with the COVID-19 disease, it was recorded that up to October 31, 2020, there were 46,414,696 cases and 1,202,167 deaths in the world [2]. Indonesia has been facing the COVID-19 disease since the first case in Indonesia which occurred on March 2, 2020, was announced directly by President Joko Widodo, in which 2 people contracted the COVID-19 virus, namely a 64-year-old mother and 31-year-old daughter [3]. As of October 31, 2020, there were 410,088 cases and 13,869 deaths in Indonesia [4]. In dealing with and preventing the increase in COVID-19, several forms and policies have been taken by the government, including implementing social distancing and large-scale social restrictions (LSSR). Social distancing means that everyone must stay away from formal forms of association, keep a distance from other people, and avoid meetings that involve many people. Large-scale social restrictions (LSSR) are restrictions imposed by local governments, but include measures such as closing public places, restricting public transportation, and restricting travel to and from restricted areas [5]. The government is taking this action because when someone who is infected with COVID-19 coughs, sneezes or talks, the COVID-19 virus will mainly spread from person to person through droplets from the nose or mouth that come out. This splash will stick around individuals, such as tables, doorknobs, and handrails, to other items and surfaces. When they inhale or touch items that an infected person has splashed and then touch their eyes, nose or mouth, that person can become infected with COVID-19.

Several models have been developed for forecasting COVID-19, for example understanding the trend of the outbreak and providing an overview of the epidemiological stage of COVID-19 in Italy, Spain and France. Prediction results for the next 10 days, April 16, 2020 to April 25, 2020, show that new cases will range between 196,520-229,147 in Italy, 204,755-257,497 in Spain, and 140,320-159,619 in France [6]. Estimated baseline reproductive number $\left(\mathrm{R}_{0}\right)$, and mortality rate and infection recovery per day for COVID-19 based on the Susceptible Infectious-Recovered-Dead (SIDR) model. There are two scenarios studied, namely using exact numbers for confirmed cases, and using x20 contaminated data $\mathrm{x} 40$ data recovered from confirmed cases. Prediction results for Hubei province on February 29,2020 , using the first scenario showed that the total number of infected cases was around 45,000-760,000, recovered 22,000-170,000, and died 2,700-34,000 [7]. Optimization Method for Forecasting Confirmed Cases of COVID-19 in China using an adaptive neuro-fuzzy 
inference system (ANFIS) model. The prediction results for the next 10 days, February 19, 2020 to February 28, 2020, show that the outbreak will reach its highest point on February 28, 2020, with the average percentage increase over the estimated period of $10 \%$, with the highest percentage occurring on February 28, 2020. at $12 \%$, and the lowest on February 19, 2020 at 8.7\% [8]. Developed the ARIMA model based on time series analysis and then used it to estimate future COVID-19 cases in India. The prediction results for the next 20 days, April 14, 2020 to May 3, 2020, show an upward trend with the lowest limit is 11,070.1, and the highest limit is $37,728.2$ [9].

There are several reports in the literature that forecast the distribution of COVID-19 in many countries around the world. Indonesia as the 4th most populous country in the world with a population of $267,026,366$ people is certainly very vulnerable to the spread of COVID-19 [10]. East Java is in the second position with the most total COVID-19 cases in Indonesia with a total of 52,465 cases, and 3,768 people died as of October 31, 2020 [11]. With the implementation of the LSSR in dealing with the spread of COVID-19, East Java as the province with the second largest population in Indonesia will certainly be greatly affected. Therefore, we created an AutoRegressive Integrated Moving Average (ARIMA) model to predict daily cases in the next 14 days with the help of $\mathrm{R}$ software. This model is expected to support medical professionals, policy makers, the general public, and make it easier us to predict how best to deal with this pandemic in the future.

\section{METHODOLOGY}

Box-Jenkins models or also known as AutoRegressive Integrated Moving Average (ARIMA) model is the development of parametric models for certain types of non-stationary time series cases. Here, we follow the ARIMA procedure in [12]. Components that contained in ARIMA model, such as Autoregressive Model (AR), Integrated (I), and Moving Average (MA).

Autoregressive Models indicates that the changing vector of interest is reduced on its own lagged values. The general formula for autoregressive model can be written as follows:

$\mathrm{Y}_{\mathrm{t}}=\phi_{1} \mathrm{Y}_{\mathrm{t}-1}+\phi_{2} \mathrm{Y}_{\mathrm{t}-2}+\ldots+\phi_{\mathrm{p}} \mathrm{Y}_{\mathrm{t}-\mathrm{p}}+\mathrm{e}_{\mathrm{t}}$

Integrated means that the data has been substituted by the difference between their values and the previous values. This separation process may have been carried out more than once. The main goal of both of these features is to ensure that the model matches the data as best as possible.

Moving Average indicates that the regression error is the amount by which an observation differs from its expected value. In truth, it is a linear combination of error terms where values have existed simultaneously and at different times in the past. The general formula for moving average model can be written as follows:

$Y_{t}=e_{t}-\theta_{1} e_{t-1}-\theta_{2} e_{t-2}-\ldots-\theta_{q} e_{t-q}$

Several steps need to be done when creating an ARIMA model, which can be seen in the flow chart in Figure 1.

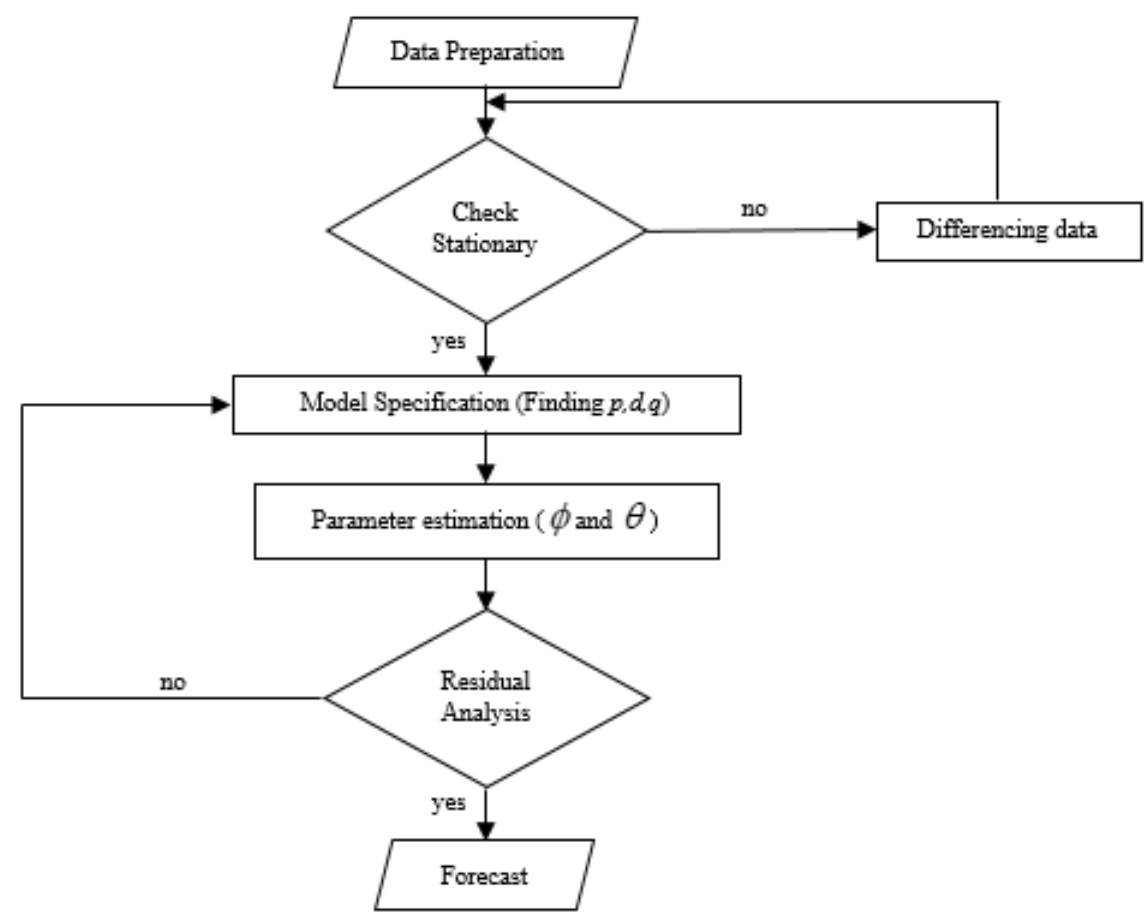

Figure 1. Flow chart of creating ARIMA model 


\subsection{Data Preparation}

Prepare the data that will be analyzed to obtain the ARIMA model. The first step of data preparation is the data collection that can be found from reliable sources. Then, do data profiling and cleansing to prevent missing data and other issues. The last one is structuring, transforming, and validating the data so that it fits the format that we can use in data modelling.

\subsection{Check Stationary}

Stationary indicates that the structural properties of a time series process do not change over time or if it has constant mean and variance, and covariance is independent of time. We can judge that data is stationary or not using R software, there are many functions that can be performed, which is:

- $A C F$ (Autocorrelation function): if the graph goes to zero then the data is stationary, and vice versa.

- $\quad A D F$ (Augmented Dickey-Fuller) test: if the p-value is less than 0.05 , then the data is stationary, and vice versa.

\subsection{Identification}

At this stage we will look for or determine $p, d$, and q. determining $\mathrm{p}$ and $\mathrm{q}$ can be done with the help of the ACF and partial auto correlation function (PACF). Meanwhile $\mathrm{d}$ is determined from the order of differencing.

- Sample autocorrelation function.

$$
r_{k}=\frac{\sum_{t=k+1}^{n}\left(Y_{t}-\bar{Y}\right)\left(Y_{t-k}-\bar{Y}\right)}{\sum_{t=1}^{n}\left(Y_{t}-\bar{Y}\right)^{2}} \text { for } k=1,2, \ldots
$$

- Sample partial autocorrelation function.

$$
\phi_{\mathrm{kk}}=\frac{\rho_{\mathrm{k}}-\sum_{\mathrm{j}=1}^{\mathrm{k}-1} \phi_{\mathrm{k}-1, \mathrm{j}} \rho_{\mathrm{k}-\mathrm{j}}}{1-\sum_{\mathrm{j}=1}^{\mathrm{k}-1} \phi_{\mathrm{k}-1, \mathrm{j}} \rho_{\mathrm{j}}}
$$

\subsection{Parameter Estimation}

If we already got $\mathrm{p}, \mathrm{d}$ and $\mathrm{q}$ from identification, then we can make the parameter estimation by some methods, there are:

\subsubsection{The method of moments estimator}

The procedure consists of equating the sample moments with the related theoretical events and implementing the resulting equations in order to obtain estimates of some uncertain parameters.

\subsubsection{The Least Squares Estimator}

Since the timing approach is unsatisfactory for certain models, we need to consider other estimation approaches. At this point, we are adding a potential nonzero mean in our stationary models and considering it as another parameter to be calculated by the least squares.

\subsubsection{Full Maximum Likelihood Estimators}

The benefit of this approach is that all the details in the data is used instead of either the first or second moments, as is the situation with the least squares. Another benefit is that certain large-scale effects are defined under very general conditions. One weakness is that for the first time, we need to focus explicitly on the joint probability density function of the method. Maximum probability or likelihood estimators are then categorized as those values for which the results currently observed are most probably to be the values that maximize the probability function.

\subsection{Diagnostic Check (Residual Analysis)}

From the residuals, a good model can be seen. If the residual is white noise, the model can be assumed to be nice and vice versa. White noise can be checked using the $\mathrm{ACF}$ and PACF residual correlations. If the ACF and PACF insignificant, it indicates residual white noise meaning the model is suitable.

\subsection{Forecasting}

After the best model is obtained, the next process is forecasting which allows us to know what will happen in the future. It is important for preparing an effective strategy in the future. So that we can better anticipate the consequences if predictions do not match expectations. A model that has produced fairly good forecasting results, of course, still needs to be developed, by following the data development in order to produce better forecasts.

\section{ANALYSIS AND EVALUATION}

\subsection{Data Preparation}

We use data on daily COVID-19 cases that have occurred in East Java from 1st April to 31th October which is available at kawalcovid19.id [4]. A summary statistics of COVID-19 cases can be seen in the Table 1, as well as the COVID-19 chart can be seen in the Figure 2. To make us more understand the trend and mean value estimation in time series analysis we can use MA, in this case, we use $\mathrm{MA}(7)$ and $\mathrm{MA}(30)$. We use moving averages since moving averages are one form of basic 
smoothing and are widely used for time series analysis and time series forecasting. By allowing this smoothing happen, we expect to remove noise and further show the signal of the cause - effect processes [13].

Table 1. Summary of COVID-19 cases

\begin{tabular}{clr}
\hline Type & Date & Cases \\
\hline Min. & $04 / 01 / 2020$ & 47.0 \\
$1^{\text {st }}$ Qu. & $05 / 24 / 2020$ & 123.0 \\
Median & $07 / 16 / 2020$ & 123.0 \\
Mean & $07 / 16 / 2020$ & 490.0 \\
$3^{\text {rd }}$ Qu. & $09 / 07 / 2020$ & 893.5 \\
Max. & $10 / 31 / 2020$ & 1398.0 \\
\hline
\end{tabular}

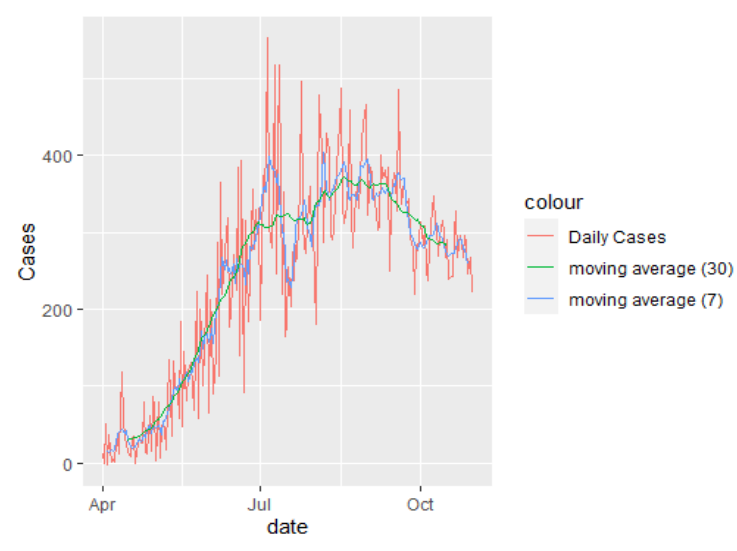

Figure 2. East Java daily cases.

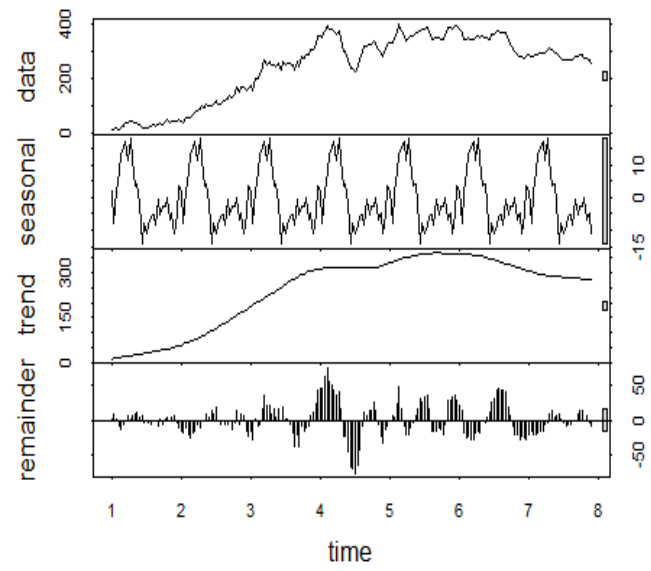

Figure 3. Decompose

Figure 3 demonstrate that our data has a trend and some seasonal components. So, we should build our data for time series and removes the most extreme observation as an outlier by its internal algorithm, so it made smoothen the portion of the peak in the curve. We can do this easily with the help of $\mathrm{R}$ software. The plot of the time series for the COVID-19 model in East Java can be seen in Figure 4.

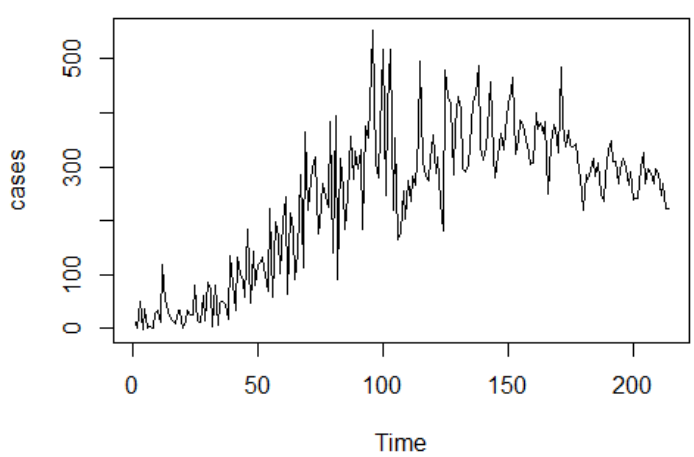

Figure 4. Time series plot

\subsection{Check Stationary}

By using the ADF function on R, it can be seen that this data is not stationary because the $p$-value is $>0.05$. Therefore, differencing data is done to produce stationary data, in this data, stationary data can be obtained in the first differencing. The difference in the ADF test before and after differentiation can be seen in Figure 5 and Figure 6, respectively.

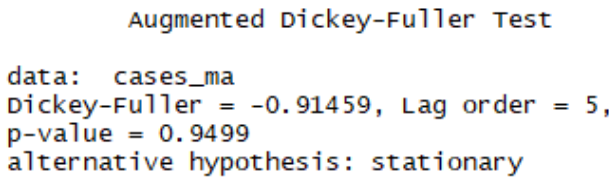

Figure 5. Before differencing.

Augmented Dickey-Fu1ler Test

data: cases_d1

Dickey-Fuller $=-5.4205$, Lag order $=5$, p-value $=0.01$

alternative hypothesis: stationary

Figure 6. After differencing.

\subsection{Identification and Parameter Estimation}

To determine the correct model, we can use the auto.arima function on $\mathrm{R}$. In this case, we got $\operatorname{ARIMA}(1,1,2)$ as our best model. But to make it better we can find the Model with a lower Akaike Information Criterion (AIC) value by seeing the ACF and PACF of ARIMA(1,1,2). Eventually, our best model is $\operatorname{ARIMA}(7,1,7)$. The plot ACF and PACF of model $\operatorname{ARIMA}(7,1,7)$ shown in the Figure 7 and Figure 8, respectively. 


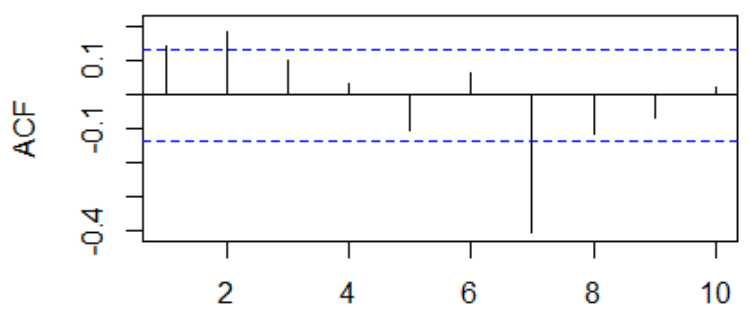

Lag

Figure 7. ACF of differenced data

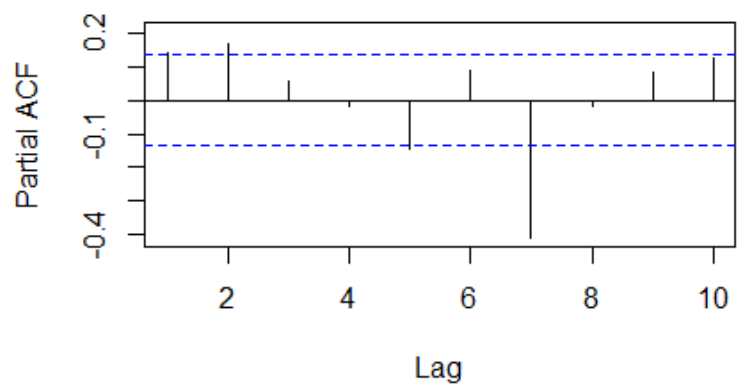

Figure 8. PACF of differenced data

We can see the difference of AIC value between $\operatorname{ARIMA}(1,1,2)$ and $\operatorname{ARIMA}(7,1,7)$ from Figure 9 and Figure 10

$\begin{array}{rrrr}\text { Coefficients: } & & & \\ \text { ar1 } & \text { ma1 } & \text { ma2 } & \text { drift } \\ 0.4933 & -0.3918 & 0.1430 & 1.2174 \\ \text { s.e. } 0.2012 & 0.2069 & 0.0713 & 1.2156\end{array}$

sigma^2 estimated as 143: log 1ikelihood $=-805.4$

AIC $=1620.81 \quad$ AIC $=1621.11 \quad$ BIC $=1637.47$

Figure 9. ARIMA $(1,1,2)$

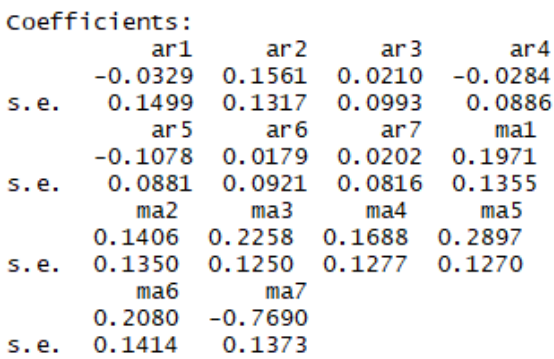

sigma^2 estimated as 77.09: log likelihood $=-752.55$, aic $=1535.09$

Figure 10. $\operatorname{ARIMA}(7,1,7)$

\subsection{Diagnostic Check (Residual Analysis)}

The residual analysis can be proven by looking at the QQ plot, histogram, Shapiro test, and Ljung Box function. As we can see from the QQ plot in Figure 11, a small deviation of the residue from the straight line can be seen from the graph. This implies that the errors are nearly standard with a few outliers. The assumption of normality is then followed. This statement is backed up by the residual histogram as we can see from Figure 12, Shapiro test that has p-value more than 0.05 as shown in Figure 13, and also plot of model residual $\operatorname{ARIMA}(7,1,7)$ that shown in Figure 14. The Ljung Box as seen in Table 2 indicates that the p-value of every lags is higher than the significance amount (0.05), which implies that there is no breach of an independent assumption. The model equation of $\operatorname{ARIMA}(7,1,7)$ is:

$$
\begin{aligned}
\mathrm{Y}_{\mathrm{t}}= & -0.0329 \mathrm{Y}_{\mathrm{t}-1}+0.1561 \mathrm{Y}_{\mathrm{t}-2}+0.0210 \mathrm{Y}_{\mathrm{t}-3}- \\
& 0.0284 \mathrm{Y}_{\mathrm{t}-4}-0.1078 \mathrm{Y}_{\mathrm{t}-5}+0.0179 \mathrm{Y}_{\mathrm{t}-6}+ \\
& 0.0202 \mathrm{Y}_{\mathrm{t}-7}+0.1971 \mathrm{e}_{\mathrm{t}-1}+0.1406 \mathrm{e}_{\mathrm{t}-2}+ \\
& 0.2258 \mathrm{e}_{\mathrm{t}-3}+0.1688 \mathrm{e}_{\mathrm{t}-4}+0.2897 \mathrm{e}_{\mathrm{t}-5}+ \\
& 0.2080 \mathrm{e}_{\mathrm{t}-6}-0.7690 \mathrm{e}_{\mathrm{t}-7}+\mathrm{e}_{\mathrm{t}}
\end{aligned}
$$

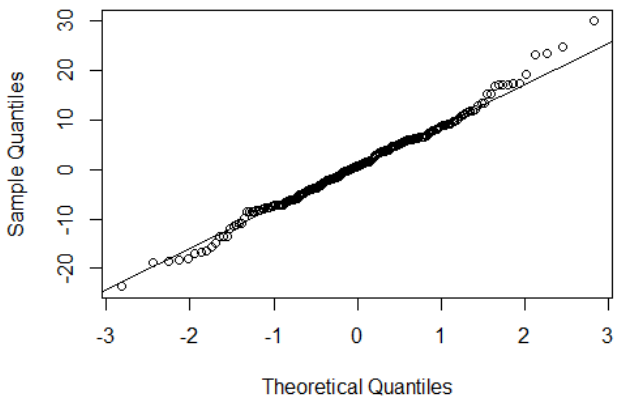

Figure 11. Normal QQ Plot

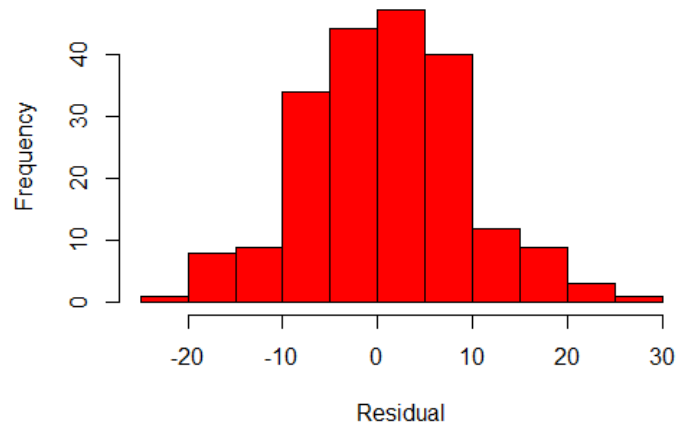

Figure 12. Histogram

Shapiro-wilk normality test

data: fit2\$residuals

$\mathrm{W}=0.99193, \mathrm{p}$-value $=0.3058$

Figure 13. Shapiro test

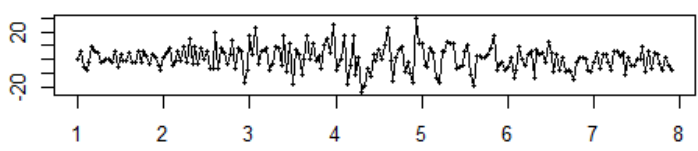

Figure 14. ARIMA $(7,1,7)$ model residual 
Table 2. Ljung-Box

\begin{tabular}{ccc}
\hline $\mathrm{X}^{2}$ & $\mathrm{df}$ & $\mathrm{p}$-value \\
\hline 0.26871 & 7 & 0.9999 \\
11.953 & 14 & 0.6101 \\
19.724 & 21 & 0.5388 \\
36.378 & 28 & 0.1332 \\
\hline
\end{tabular}

\subsection{Forecasting}

The forecasting of COVID-19 confirmed cases and their lower and upper limits for 14 days, November 1 , 2020 to November 14, 2020, with 99\% confidence interval $(\mathrm{CI})$ can be seen in Table 3, followed by forecasting plot shown as blue line in Figure 15.

Table 3. Comparison between forecasting COVID-19 cases and real data

\begin{tabular}{ccccc}
\hline Date & Forecast & Lower limit & Upper limit & Real data \\
\hline $11 / 1 / 2020$ & 262.4969 & 239.6583 & 285.3355 & 253 \\
$11 / 2 / 2020$ & 256.4356 & 221.3344 & 291.5367 & 284 \\
$11 / 3 / 2020$ & 253.2447 & 204.9949 & 301.4946 & 272 \\
$11 / 4 / 2020$ & 256.9856 & 194.9229 & 319.0483 & 239 \\
$11 / 5 / 2020$ & 252.9956 & 177.4712 & 328.5199 & 278 \\
$11 / 6 / 2020$ & 255.4209 & 166.0911 & 344.7508 & 289 \\
$11 / 7 / 2020$ & 261.2948 & 157.5129 & 365.0766 & 269 \\
$11 / 8 / 2020$ & 261.3800 & 151.5588 & 371.2011 & 282 \\
$11 / 9 / 2020$ & 261.8753 & 146.0491 & 377.7015 & 234 \\
$11 / 10 / 2020$ & 262.3598 & 141.6683 & 383.0513 & 272 \\
$11 / 11 / 2020$ & 261.9985 & 136.7857 & 387.2114 & 168 \\
$11 / 12 / 2020$ & 261.4238 & 131.9294 & 390.9182 & 270 \\
$11 / 13 / 2020$ & 261.5275 & 127.4212 & 395.6339 & 239 \\
$11 / 14 / 2020$ & 261.4797 & 122.9993 & 399.9601 & 256 \\
\hline
\end{tabular}

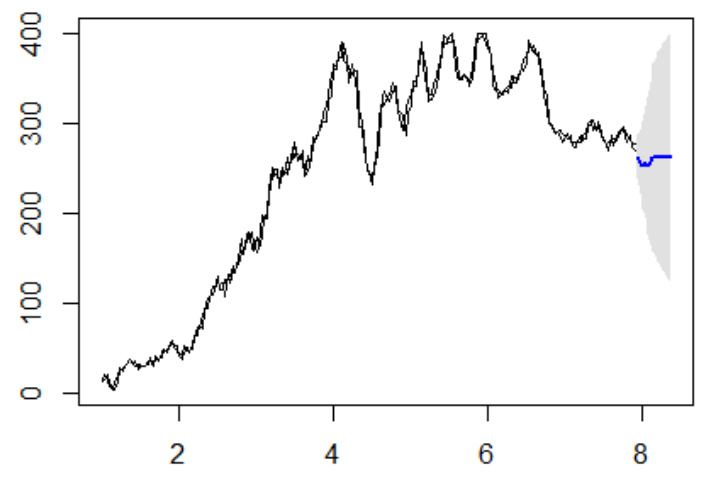

Figure 15. Forecasts from $\operatorname{ARIMA}(7,1,7)$

\section{CONCLUSION}

In this work, we found the best ARIMA model for predicting COVID-19 over the next 14 days. The dataset used is daily COVID-19 cases in East Java from April 1, 2020 to October 31, 2020 [4]. The results showed that the $\operatorname{ARIMA}(7,1,7)$ is the best model for this case where the mathematical model are expressed below.

$$
\begin{aligned}
\mathrm{Y}_{\mathrm{t}}= & -0.0329 \mathrm{Y}_{\mathrm{t}-1}+0.1561 \mathrm{Y}_{\mathrm{t}-2}+0.0210 \mathrm{Y}_{\mathrm{t}-3}- \\
& 0.0284 \mathrm{Y}_{\mathrm{t}-4}-0.1078 \mathrm{Y}_{\mathrm{t}-5}+0.0179 \mathrm{Y}_{\mathrm{t}-6}+ \\
& 0.0202 \mathrm{Y}_{\mathrm{t}-7}+0.1971 \mathrm{e}_{\mathrm{t}-1}+0.1406 \mathrm{e}_{\mathrm{t}-2}+ \\
& 0.2258 \mathrm{e}_{\mathrm{t}-3}+0.1688 \mathrm{e}_{\mathrm{t}-4}+0.2897 \mathrm{e}_{\mathrm{t}-5}+ \\
& 0.2080 \mathrm{e}_{\mathrm{t}-6}-0.7690 \mathrm{e}_{\mathrm{t}-7}+\mathrm{e}_{\mathrm{t}}
\end{aligned}
$$

Forecast results for 14 days from November 1, 2020 to November 14, 2020, using the model are compared with the actual data display the fairly decent result, where all the actual data is included in the forecast interval. These research results will be good input in helping medical professionals, regulators, and the general public, especially in the East Java area to deal with this pandemic in the future.

\section{AUTHORS' CONTRIBUTIONS}

A H Ulya contributed to data collection, visualization making, ARIMA programming, and analysis using R. E $\mathrm{S}$ Nugraha provides an analysis of $\mathrm{R}$ programming, and perfecting the overall manuscript. All authors revised the paper critically and approved the final manuscript. 


\section{ACKNOWLEDGMENTS}

The author would like to thank the anonymous referee who carefully read the original paper and gave a lot valuable comments and suggestions to improve the quality of this manuscript.

\section{REFERENCES}

[1] J. Ma. "Coronavirus: China's First Confirmed Covid-19 Case Traced Back to November 17." scmp.com. https://www.scmp.com/news/china/society/article/ 3074991/coronavirus-chinas-first-confirmed-covid19-case-traced-back (accessed Nov. 12, 2020).

[2] "Coronavirus Graphs."

Worldwide htps://www.worldometers.info/coronavirus/world wide-graphs/\#total-cases (accessed Nov. 1, 2020).

[3] J. Akbar. "Perjalanan Pandemi Covid19 di Indonesia." kompas.com. https://www.kompas.com/tren/read/2020/07/28/06 0100865/perjalanan-pandemi-covid-19-diindonesia-lebih-dari-100.000-kasus-dalam5 ? page $=$ all (accessed Oct. 31, 2020).

[4] Kawal Covid19, Nov 2020, "Kasus Covid19 di Indonesia." kawalcovid19.id. [Online]. Available: https://experience.arcgis.com/experience/bf4eb5d7 6e98423c865678e32c8937d4 (accessed Nov. 1, 2020).

[5] "Pembatasan

Sosial

Berskala

Besar." kemenkopmk.go.id. https://www.kemenkopmk.go.id/pembatasansosial-berskala-besar (accessed Nov. 2, 2020).

[6] Z. Ceylan, "Estimation of COVID-19 prevalence in Italy, Spain, and France," Sci. Total Environ., vol. 729, no. 138817, pp. 1-7, Aug. 2020.

[7] C. Anastassopoulou, L. Russo, A. Tsakris, and C. Siettos, "Data-based analysis, modelling and forecasting of the COVID-19 outbreak," PloS one, vol.15, no. 3, pp. 1-21, Mar. 2020. Accessed on Nov. 12, 2020. [Online]. Available: doi: https://doi.org/10.1371/journal.pone.0230405.

[8] Al-qaness Mohammed A. A., A. A. Ewees, H. Fan, and M. Abd El Aziz, "Optimization Method for Forecasting Confirmed Cases of COVID-19 in China," Journal of Clinical Medicine,vol. 9, no. 3, p. 674, Mar. 2020. Accessed on Nov. 12, 2020. [Online]. Available: http://dx.doi.org/10.3390/jcm9030674.

[9] H. Tandon, P. Ranjan, T. Chakraborty, and V. Suhag, "Coronavirus (COVID-19): ARIMA based time-series analysis to forecast near future," 2020. [Online]. Available: arXiv:2004.07859.

[10]"U.S. Census Bureau Current Population." census.gov. https://www.census.gov/popclock/print.php?compo nent=counter (accessed Nov. 13, 2020).

[11] R. Austen. "Statistik Covid19 per Provinsi." kawalcovid19.id. https://kawalcovid19.id/ (accessed Nov. 13, 2020).

[12] J. D. Cryer and K. S. Chan, "Models for Non Stationary Time Series" in Time series analysis: with applications in R, second Ed. NY, New York, USA: Springer Science and Business Media, 2008, pp. 87-102.

[13] K. Strom, "Introduction to construction statistics using Excel.“ sciencedirect.com. https://www.sciencedirect.com/topics/engineering/ moving-average (accessed Nov. 11, 2020). 